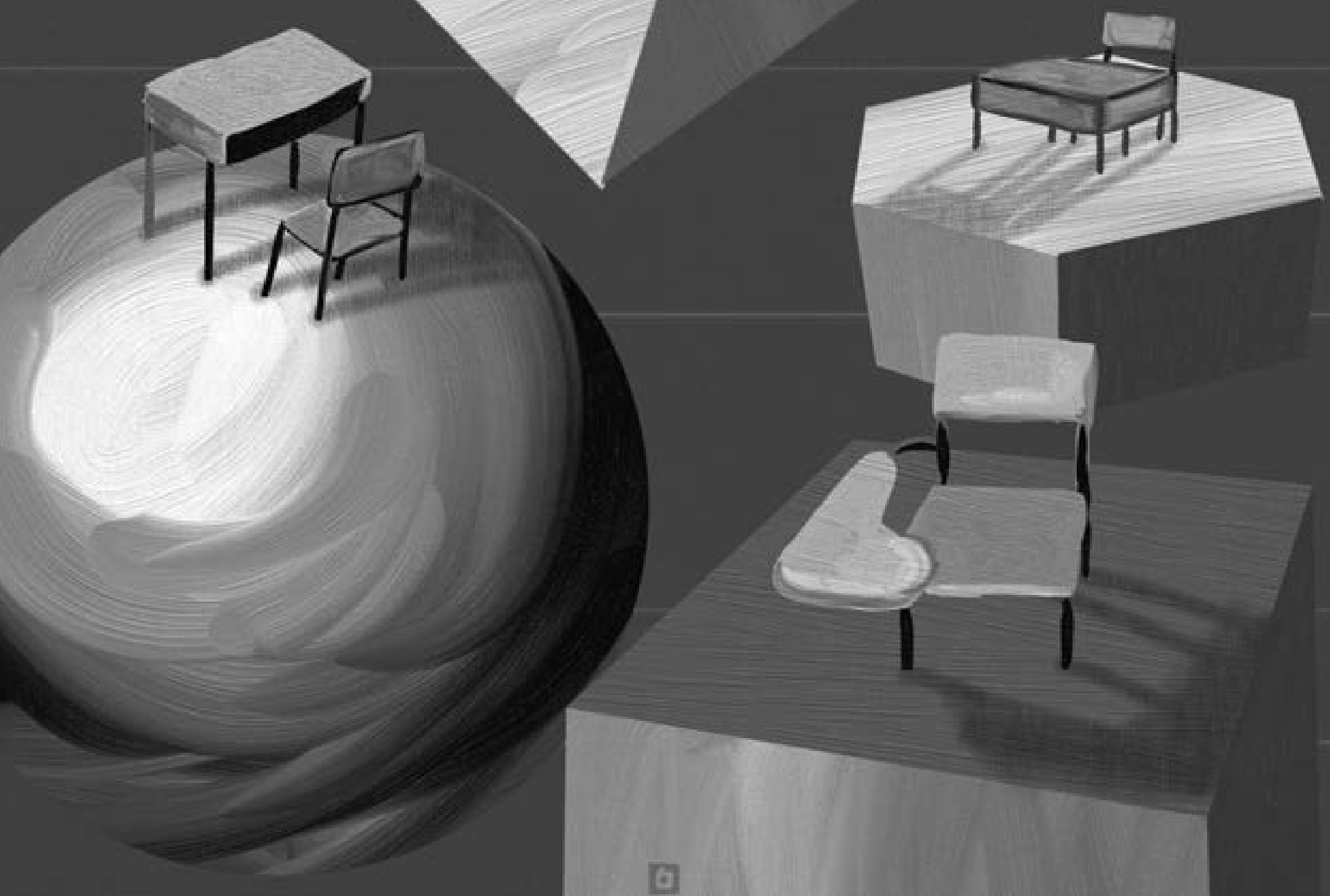

\title{
El derecho a la educación: su valoración desde las vivencias situadas y diferenciadas de los y las estudiantes en el contexto escolar'
}

The right to education: its assessment and differentiated from situated experiences of the students in the school context

O direito à educação: sua valoração desde as vivências situadas e diferenciadas dos e as estudantes no contexto escolar

Constanza Amézquita Quintana

1 Los planteamientos señalados en este artículo son producto de las reflexiones y la construcción colectiva con funcionarios y equipos de trabajo del IDEP en el Componente Educación y Políticas Públicas durante los años 2012 y 2014. Se han tomado ideas y apartes de productos académicos institucionales inéditos de Omar Orlando Pulido, Paula González y Fernando Rincón. 


\section{Constanza Amézquita Quintana ${ }^{2}$}

2 Investigadora Principal del Estudio General con Desarrollos Temáticos para Recomendaciones a la Política Educativa del IDEP. Socióloga y Maestría en Sociología de la Universidad Nacional de Colombia. Candidata a Doctora en Estudios Políticos y Relaciones Internacionales - IEPRI- de la Universidad Nacional de Colombia.

Correo electrónico: constanza.amezquita@gmail.com

Fecha de recepción: 19 de junio de 2014 / fecha de aprobación: 21 de julio de 2014

\section{Resumen}

Este texto pretende iniciar una reflexión en torno a las potencialidades del concepto vivencia situada y diferenciada para valorar el derecho a la educación de los y las estudiantes en el contexto escolar. Para ello, se exploran los orígenes de esta noción desde la filosofía hermenéutica y se sugiere una mirada vivencial de los saberes y las experiencias de las y los escolares en los colegios de Bogotá. Lo anterior en el marco de los debates que han tenido lugar en el Estudio General con Desarrollos Temáticos para Recomendaciones a la Política Educativa del Instituto para la Investigación Educativa y el Desarrollo Pedagógico (IDEP).

Palabras clave: Vivencias situadas y diferenciadas, derecho a la educación, valoración, sujetos, saberes, prácticas.

\section{Summary}

This text aims to initiate a reflection on the potential of situated and differentiated experience to assess the right to education of the students in the school context concept. To do this, the origins of this notion is explored hermeneutic philosophy and experiential knowledge look and experience of school and colleges in Bogotá is suggested. This part of the discussions that have taken place in the General Development Studio Theme for Educational Policy Recommendations to the Institute for Educational Research and Pedagogical Development (IDEP).

\section{Keywords: Located and} differentiated experiences, right to education, assessment, subjects, knowledge, practices.

\section{Resumo}

Este texto pretende iniciar uma reflexão em torno das potencialidades do conceito vivência situada e diferenciada para valorizar o direito à educação dos e as estudantes no contexto escolar. Para isso, se exploram as origens desta noção desde a filosofia hermenéutica e se sugere uma mirada vivencial dos saberes e as experiências das e os escolares nos colégios de Bogotá. $\mathrm{O}$ anterior no marco dos debates que têm tido lugar no Estudo Geral com Desenvolvimentos Temáticos para Recomendações à Política Educativa do Instituto para a Investigação Educativa e o Desenvolvimento Pedagógico (IDEP).

\section{Palavras chave: Vivências} situadas e diferenciadas, direito à educação, valoração, sujeitos, saberes, práticas. 


\section{El derecho a la educación y su valoración desde los sujetos}

A unque el esquema analítico 4As - planteado por Tomasevski- para la valoración del derecho a la educación logró crear un lenguaje compartido por gobiernos y organizaciones internacionales gubernamentales y no gubernamentales frente al avance del derecho, su énfasis ha estado en las obligaciones del Estado en materia de educación y se ha dejado de lado el modo como los sujetos vivencian tal derecho en el contexto escolar.

A su vez, el abordaje del derecho desde el esquema 4A suele ir acompañado, por lo general, de mediciones de talante cuantitativo y de la aplicación de pruebas estandarizadas de conocimientos a nivel nacional - para la "medición" de la calidad educativa y la generación de clasificaciones internacionales-.

Con este antecedente se plantea la necesidad de proponer un giro conceptual y metodológico que evite el riesgo de dejar de lado las condiciones individuales y colectivas de las personas en las que se realiza el derecho, así como los efectos y las posibilidades generados por éste en los sujetos. Con ello, se trata de valorar el cumplimiento del derecho no sólo a partir del cumplimiento de las obligaciones del Estado, sino especialmente, desde el cuidado necesario a la realización de los derechos en las personas, consideradas como sujetos y no solo como individuos.

En este sentido, proponemos que la valoración del derecho a la educación en los sujetos debe darse desde las vivencias situadas y diferenciadas de los y las estudiantes en el contexto escolar. Ello implica 'historizar' la mirada, reconociendo los lugares donde se ubican socialmente las y los estudiantes para asumir y ejercer su derecho a la educación, como un factor de agencia humana entendida en este caso como la autonomía de las y los estudiantes para la construcción de su proyecto de vida-.

Para ello, a continuación daremos un vistazo a la noción de vivencia situada y diferenciada, explorando sus orígenes en la filosofía hermenéutica.

\section{La noción de vivencia en la filosofía hermenéutica}

El hombre debería aprender a detectar y a estar al acecho de este destello de luz que cruza su mente en el interior más que el brillo de los bardos y de los sabios en el firmamento. No obstante, menosprecia su pensamiento sin darse cuenta de que es suyo. En cada obra genial reconocemos nuestros propios pensamientos, a los que atribuimos poco valor; regresan a nosotros con una cierta majestad ajena. Grandes obras de arte no encierran para nosotros más lección que nos pueda interesar que ésta. Nos enseñan a dejarnos llevar por nuestra impresión espontánea con una inflexibilidad no exenta de buen humor, particularmente cuando la mayor parte de los gritos se oye de la otra parte. De otra suerte, mañana expondrá un extraño, con magistral buen sentido, precisamente lo que nosotros pensábamos y sentíamos de continuo, y nos veremos obligados a tomar de otro, con vergüenza, nuestra propia opinión (Emerson, 2007: 131).

Aunque en el lenguaje cotidiano se hable con bastante frecuencia del término vivencia- en tanto experiencia vivida por una persona y que influye en su carácter-, este tiene una larga trayectoria, vinculada a la tradición hermenéutica en las ciencias sociales.

Es importante comenzar diciendo que la hermenéutica antes de consolidarse como una tradición filosófica, había recorrido un largo camino en la interpretación de textos religiosos, literarios e históricos. Para esta corriente es clave la comprensión del sentido de la acción y la reflexividad del sujeto sobre su experiencia -en tanto capacidad de reflexionar acerca de su existencia y de trascender en la práctica al actuar en consecuencia-. Justamente, acá la noción de vivencia hace parte de este proceso comprensivo llevado a cabo por el sujeto.

Así por ejemplo, para un autor como Wilhelm Dilthey la comprensión y la explicación caracteriza a las ciencias del espíritu, por cuanto las dota de un contenido y un método distinto a las ciencias de la naturaleza: "Tenemos, pues, que este grupo de ciencias constituye un campo propio que se halla bajo leyes propias fundadas en la naturaleza de lo vivible, expresable y comprensible" (Dilthey, 1944: 92). Entretanto, para Heidegger la comprensión trasciende las pautas metodológicas y constituye un atributo propio del ser humano -una "determinación ontológica del hombre”- (De la Maza, 2005: 122).

De un modo semejante, para Husserl -fundador de la fenomenología-, la comprensión ofrece al hombre un método reflexivo para dejar que "las cosas mismas" se revelen tal como se dan inmediatamente para quien las vive-dejando de lado el juicio sobre la validez de las interpretaciones-. Esto es posible gracias a la intencionalidad del sujeto -que lleva a que la conciencia esté siempre abierta y referida a un contexto amplio: "Este contexto es el mundo, horizonte general de todo lo que es y puede llegar a ser contenido de la experiencia” (2005: 123). 
Para Edmund Husserl la "reducción fenomenológica” implica contemplar "las cosas mismas" con una mirada neutral, ahistórica, libres de prejuicios y de cargas axiológicas y culturales que impidan describir los fenómenos tal como se manifiestan a la conciencia (De La Maza, 2005: 127). Al respecto, García-Baró considera que la reducción fenomenológica es:

La manifestación de la totalidad posible del sentido del mundo

[...], es la consecuencia teorética y práctica de la decisión de proponerse $[\ldots]$ entrar en la plenitud de la responsabilidad, que comienza por el hecho de ser enteramente responsable el hombre de sí mismo y ante sí mismo, en su radical soledad. Es, pues, la verdadera madurez de la vida humana (García- Baró, 1997).

Sin embargo, para Heidegger dejar de lado la historia solo sirve para encubrir los prejuicios operantes en toda descripción que se vale de conceptos, en tanto todos los conceptos están saturados de tradición y de teoría. Por eso, para tener una relación libre con la historia y comprender algo en tanto que algo es clave identificar el sentido o el hacia dónde de lo que se comprende: "Sentido es el horizonte del proyecto, estructurado por el haber-previo, la manera previa de ver y la manera de entender previa, horizonte desde el cual algo se hace comprensible en cuanto algo" (Heiddeger, 1997: 9, citado en De La Maza, 2005: 128).

Para este autor alemán, el sentido es una estructura del hombre en tanto que Dasein, no algo que esté adherido a los entes, ni flotando en algún espacio ideal. En ese hacia dónde lo que se interpreta se posee ya de antemano, recortado o perfilado de una cierta manera y acompañado de una cierta conceptualización. Si la interpretación se mueve dentro de lo ya comprendido y se nutre de ello, entonces se mueve en un círculo. Pero no se trata de un círculo vicioso, sino de un círculo hermenéutico. Es decir, no es un círculo que haya que eliminar del saber, sino uno donde hay que entrar de manera adecuada (De La Maza, 2005: 128).

Finalmente, Hans-Georg Gadamer -quien fue alumno de Heidegger- considera que la comprensión es una reflexión sobre lo que acontece con el hombre cuando efectivamente interpreta su presente en relación con la historia, en tanto esta le permite "la mediación del pensamiento con la vida actual". Para este autor, la comprensión es posible, en principio, gracias al lenguaje, como un medio que permite el desvelamiento del sentido de la acción al tiempo que permite el entendimiento mutuo. Al decir de De la Maza: "Sin la posibilidad de la representación lingüística no tendría sentido pretender que verdaderamente se comprende algo, y no hay nada acerca de lo cual no pueda decirse alguna cosa con sentido" (De La Maza, 2005: 135).
Es justamente Gádamer quien en su texto Verdady método rastrea la aparición de la noción de vivencia en el ámbito alemán - erlebnis-, e identifica una primera referencia a este concepto en Hegel, y encuentra que su popularización en la década de los años setenta tiene que ver con la notoriedad de la literatura biográfica. Además, cuando rastrea el término derivado de experiencia - erleben-, entendido como el "estar todavía en vida cuando tiene lugar algo", encuentra alusión a esta palabra en la literatura biográfica del siglo XIX de poetas como Goethe, cuyo objetivo radica en entender la obra desde la vida. En adición a ello, Gadamer destaca la influencia del idealismo alemán -con su apelación al sentimiento vivo, a la vida, por oposición a la objetividad y frialdad del racionalismo- en el repunte de la idea y de la noción de vivencia. $\mathrm{Al}$ decir de este autor:

El concepto de la vida constituye también el trasfondo metafísico que sustenta el pensamiento especulativo del idealismo alemán, y que desempeña un papel fundamental tanto en Fichte y en Hegel como en el propio Schleiermacher [...] La apelación de Schleiermacher al sentimiento vivo frente al frío racionalismo de la Ilustración, el llamamiento de Schiller hacia una libertad estética frente al mecanismo de la sociedad, la oposición hegeliana de la vida (más tarde: del espíritu) frente a la «positividad» son los precedentes de una protesta contra la moderna sociedad industrial que convirtió a comienzos de nuestro siglo las palabras vivir y vivencia en palabras redentoras de resonancia casi religiosa (Gadamer, 1993: 99).

También destaca que la noción de "lo vivido" - das erlebteda cuenta tanto de la inmediatez de la experiencia, de "lo vivido por uno mismo" -que antecede toda interpretación- como de la permanencia de aquello que ha sido vivido. Así lo menciona el alumno de Heidegger: "Este contenido es como un resultado o efecto, que ha ganado permanencia, peso y significado respecto a los otros aspectos efímeros del vivir (Gadamer, 1993: 97).

Desde el punto de vista de este autor, la noción de vivencia erlebnis- se sitúa en un punto intermedio entre las dos significaciones de la noción experiencia - erleben-:

Cuando algo es calificado y valorado como vivencia se lo piensa como vinculado por su significación a la unidad de un todo de sentido. Lo que vale como vivencia es algo que se destaca y delimita tanto frente a otras vivencias - en las que se viven otras cosas- como frente al resto del decurso vital -en el que no se vive 'nada' (Gadamer, 1993: 103)-.

Continúa el autor señalando que: "algo se convierte en una vivencia en cuanto que no sólo es vivido, sino que el hecho de que lo haya sido, ha tenido algún efecto particular que le ha conferido un significado duradero" (97). 
el término locación o localización hace referencia a "los múltiples loci-raza, género, clase, etc.- desde los cuales enunciamos, así como también las diversas localizaciones que ocupamos en las divisiones sociales de trabajo y poder - a nivel local, nacional y global-" (Lao-Montes, 2001: 14).

De este modo, en el contexto escolar proponemos que las vivencias de los y las estudiantes -en relación con el derecho a la educación- se contemplen como una amalgama de prácticas y saberes -en el sentido amplio del término- ${ }^{3}$ situados y diferenciados - desde sus circunstancias sociohistóricas y posiciones concretas de sujetos-, es decir, in-corporados, encarnados en sujetos atravesados por contradicciones sociales; vinculados a luchas específicas y ampliamente diversos en términos de género, raza, clase, integridad cultural, identidades, pertenencia étnica y geográfica.

En consecuencia, considerar las vivencias como una fusión de prácticas y saberes situados requiere de un enfoque que privilegie la interpretación de los discursos de las y los sujetos a partir de la reconstrucción de las condiciones sociales e históricas de la producción, la circulación y la recepción de las narrativas, teniendo en cuenta sus escenarios espacio-temporales, sus campos de interacción, las instituciones sociales que los rodean y la estructura social a la que pertenecen.

Cabe agregar que destacamos el rol del contexto escolar en tanto la escuela constituye -como institución social- el marco de relaciones sociales más concreto donde los y las estudiantes ejercen y disfrutan el derecho a la educación, a la vez que amplían la comprensión del éste.

Justamente es en el contexto escolar donde las y los estudiantes construyen sus propias comprensiones y expectativas respecto a la educación, sobre lo que les gustaría aprender y hacer, sobre los problemas que los aquejan y sobre el modo como la educación que reciben posibilita-transforma-configura sus expectativas futuras y planes vitales, entre otras cuestiones. En tanto sujetos del derecho a la educación sus voces requieren ser escuchadas.

Sin embargo, con frecuencia estas se han desestimado y han permanecido separadas de la valoración del derecho a la educación, debido a la gran distancia que existe entre el lenguaje de los alumnos y el de docentes, padres, madres y Estado -que recordemos es el lenguaje dominante en el esquema 4A-, y a la tendencia señalada por Ruddock, et al. (1996) a infantilizarlos y estigmatizarlos, aplicando una supuesta ideología de la inmadurez y la inexperiencia. Como señala Martínez en relación con el desconocimiento de las voces de las y los estudiantes por parte de las y los docentes en el contexto escolar:

Desconocemos lo que piensa y dice el alumnado como consecuencia de que no lo escuchamos. Los estudiantes se expresan continuamente y narran sus vivencias de manera bastante natural. Sin embargo, no escuchamos lo que dicen. No utilizamos criterios o formas estratégicas para poder atender al contenido de las expresiones del alumnado (Martínez, 1998: 56).

Con esto, se olvida que el derecho a la educación trasciende la visión de los deberes u obligaciones del Estado y cobra vida cuando potencia las capacidades y libertades de los y las estudiantes y, particularmente, en tanto incrementa su autonomía-responsabilidad, sin discriminación, para la construcción de su plan o proyecto de vida. Al respecto, destacamos los planteamientos de Amartya Sen (1999), para quien las capacidades comprenden aquellas oportunidades reales y actuales que las personas tienen para tomar decisiones informadas, para poder garantizarse una vida y las actividades que tienen razones para valorar. De acuerdo con Senn, las capacidades son potencialidades, oportunidades reales que se concretan en seres beings y haceres doings que la persona valora y puede efectivamente ser-hacer, liberado de las ataduras unfreedoms que dejan a las personas con poca capacidad de elección y pocas oportunidades para ejercer su agencia (Sen, 1999).

Lo anterior implica dejar de lado la concepción de las y los estudiantes como simples receptores pasivos de las disposiciones estatales en materia del derecho a la educación o "sujetos al derecho", y-en vez de ello- reconocerlos como protagonistas del proceso educativo y sujetos incidentes en este -sujetos que "son parte del proceso educativo, que toman parte en él y que tienen parte en su transformación y en la ampliación de su comprensión, es decir "sujetos del derecho"-. En consecuencia,

$3 \mathrm{Al}$ respecto, consideramos que los saberes de las y los estudiantes no se agotan en sus aprendizajes y habilidades "formales", sino que abarcan los saberes de los sujetos sobre sí, sobre el mundo, sobre los otros y sobre sus relaciones con ellos, e implica prestar atención a lo que se internaliza, a lo que se ignora y a lo que se desmiente. Como lo menciona Frigeiro (2010), “cada sujeto está concernido por los saberes -sobre sí, sobre el mundo, sobre los otros y sus relaciones con ellos-. Cada saber -su ignorancia, su desmentida, su internalización- afecta y altera al sujeto, que por su parte altera al mundo cuando sobre él pone sus palabras, teje sus hipótesis - profanas, paganas, científicas, preteóricas, intuitivas, sensibles, creativas, transgresoras, ingenuas, elaboradas, inteligibles, tranquilizadoras, sobrecogedoras e inquietantes en múltiples e infinitas combinaciones-" (Frigeiro, 2010: 18). 


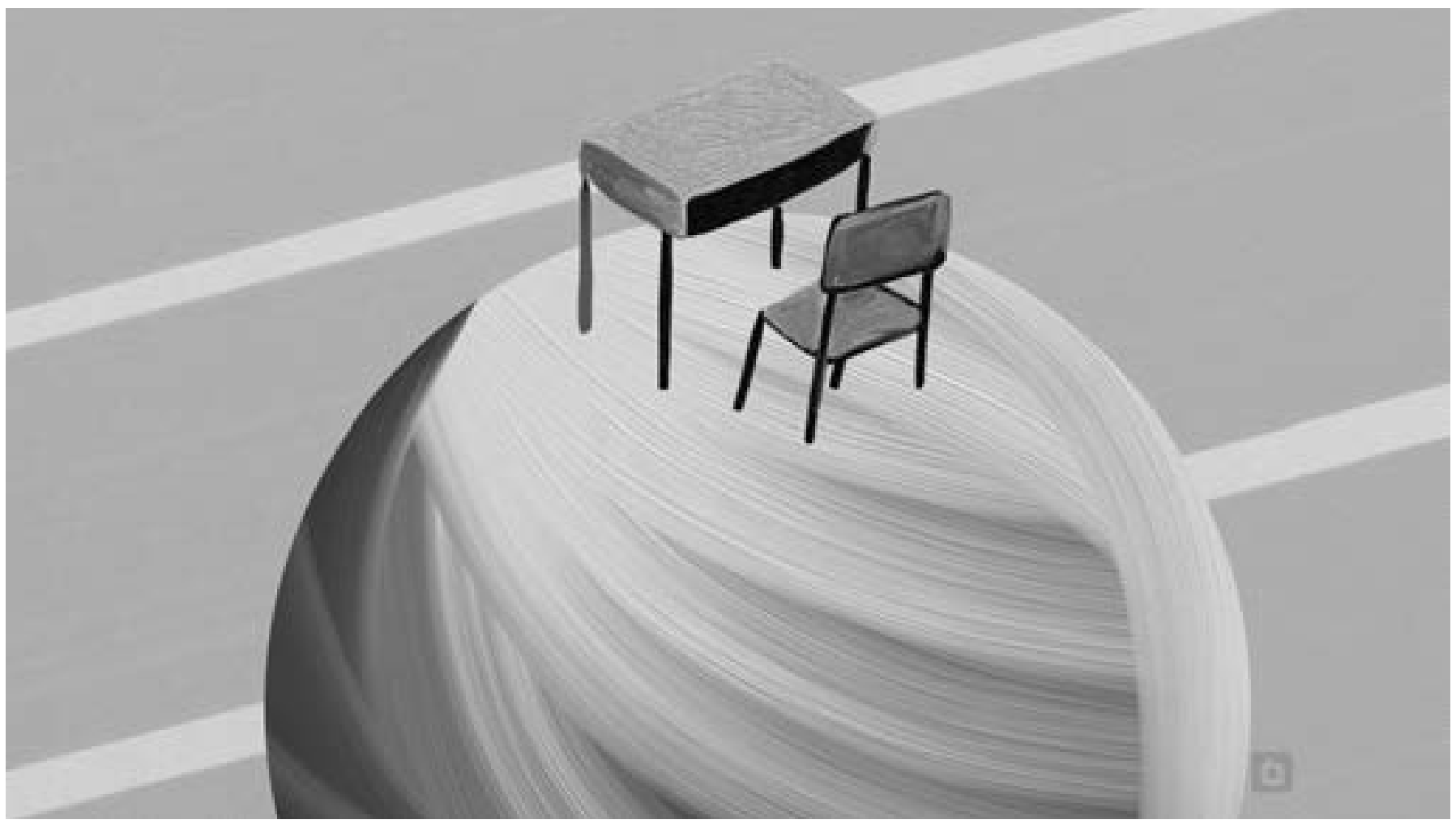

\section{Conclusión}

Desde el equipo del Estudio General con Desarrollos Temáticos para Recomendaciones a la Política Educativa del Instituto para la Investigación Educativa y el Desarrollo Pedagógico (IDEP) se destaca la importancia de valorar el derecho a la educación accediendo a la cotidianidad de la escuela en clave de las vivencias situadas y diferenciadas de los y las estudiantes en el contexto escolar. Lo anterior implica reconocer la capacidad que tienen para transformar su entorno y para construir su proyecto de vida, sociedad y mundo; reconocer los diversos escenarios del contexto escolar que entran en juego en la construcción de saberes y del proyecto de vida y considerar el derecho a la educación como un factor que hace posible la agencia humana, valorado desde la autonomía que este les brinde para la construcción de su proyecto de vida.

En consecuencia, al hablar de vivencias situadas y diferenciadas es imperativo tener en cuenta las distintas prácticas y los saberes que circulan en el contexto escolar, considerando que estos se encuentran in-corporados, encarnados en sujetos atravesados por contradicciones sociales, vinculados a luchas concretas y ampliamente diversos en términos de género, raza, clase, integridad cultural, identidades, pertenencia étnica y geográfica.

Lo anterior implica dejar de lado la concepción de las y los estudiantes como simples receptores pasivos de las disposiciones estatales en materia del derecho a la educación $-\mathrm{O}$ "sujetos al derecho"- , y en vez de ello, reconocerlos como protagonistas del proceso educativo y sujetos incidentes; sujetos que "son parte del proceso educativo, que toman parte en él y que tienen parte en su transformación y en la ampliación de su comprensión, es decir "sujetos del derecho". En consecuencia, solo mediante el acceso a sus vivencias, entendidas como aquellas experiencias significativas que dejan huella en la personalidad y que son resultado de la relación del sujeto con los otros sujetos, con los objetos, artefactos, instituciones y eventos que constituyen su contexto, será posible acceder a sus significados y perspectivas sobre el proceso educativo y, por esta vía, sobre el ejercicio en contexto del derecho a la educación. 


\section{Referencias}

Alba Lobato, E. et al. (2010). Estudio encuesta. Métodos de investigación. $3^{\circ}$ Educación Especial.

Alcaldía Mayor de Bogotá. (29 de febrero de 2012). Plan de desarrollo económico y social y de obras públicas para Bogotá Distrito Capital 2012-2016 Bogotá Humana. Bogotá.

Alcaldía Mayor de Bogotá. Secretaría de Educación. (2004). Plan Sectorial de Educación 2004-2008. Bogotá una Gran Escuela. Recuperado el 21 de abril de 2013, de http://www.sedbogota.edu.co/AplicativosSED/Centro_Documentacion/anexos/publicaciones_2004_2008/plan_sectorial_2004_08.pdf

Ander-Egg, E. (febrero, 2005). Reflexiones en torno al significado y alcance de la participación. Disponible en http://www.joveselx.com/dinamia/

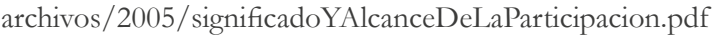

Cejudo, R. (2007). Capacidades y libertad. Una aproximación a la teoría de Amartya Sen. Revista Internacional de Sociología (RIS) Vol. LXV, Nro. 47, mayo-agosto, 9-22.

Conde, F. (1994). "Procesos e instancias de reducción/formalización de la multidimensionalidad de lo real: procesos de institucionalización/reificación social en la praxis de la investigación social”, En: Delgado, J. M. \& Gutiérrez, J. (1994). Métodos y técnicas cualitativas de investigación social. Madrid, España: Editorial Síntesis S.A.

Congreso de Colombia. (Febrero de 1994). Ley 115 Ley General de Educación. Diario Oficial (41.214). Bogotá: Imprenta Nacional.

Congreso de Colombia. (22 de enero de 1991). Ley 12 por la cual se aprueba la Convención de los Derechos del Niño. Diario Oficial Nro. 39. 60. Bogotá: Imprenta Nacional.

Dávila A. \& Laó-Montes A. (2001). Mambo Montage: The Latinization of New York. Columbia: University Press.

De La Maza, L. M. (2005). Fundamentos de la filosofía hermenéutica: Heidegger y Gadamer. Teología y vida Vol. XLVI, p. 122-138. Santiago: Instituto de Filosofía Pontificia Universidad Católica de Chile.

Dilthey, W.(1944). Fundación de las ciencias del espíritu. En El mundo bistórico (p. 42).México: Fondo de Cultura Económica.
Durán, E. (2007). Los derechos de los niños y las niñas: marco general y puntos de debate. En D. (Eds.). Derechos de los niños y las niñas. Debates, realidades y perspectivas. Bogotá: Universidad Nacional de Colombia. Facultad de Ciencias Humanas.

Emerson, R. W. (2007). Ensayos. Tercera edición. México: Editorial Porrúa.

Frigerio, G. (2010).“Curioseando”. Frigerio \& Diker. Educar: saberes alterados. Colección Del Estante. La Hendija.

Gadamer, H. (1993). Verdad y método. Fundamentos de una hermenéutica filosófica. Ediciones Salamanca: Sígueme.

García-Baró, M. (1997). La génesis de la reducción y los orígenes líricos de la filosofía. La posibilidad de la fenomenología. Madrid: Editorial Complutense.

Gentili, P. (s.f.). El neoliberalismo amenaz̧a el carácter público de la enseñanza Recuperado el 21 de abril de 2013, de Universidad de Santiago de Compostela USC Firgoa: http://firgoa.usc.es/drupal/node/4673.

Gentili, P. (21 de abril de 2013). La exclusión y la escuela: El apartheid educativo como política de ocultamiento. Obtenido de Laboratorio de Políticas Públicas (LPP) Universidad del Estado de Río de Janeiro: http:/ / www.inau.gub.uy/biblioteca/gentili.pdf

Heidegger, M. (1997). Sery tiempo. Trad. de J. E. Rivera. Santiago de Chile: Editorial Universitaria.

Martínez, J. B. (1998). ¿Tiene el alumnado posibilidad o derecho a realizar innovaciones? Volver a pensar la educación, vol. II. Madrid: Ediciones Morata.

Nicastro, S. (2005). Los proyectos en la escuela: Algunas reflexiones desde una mirada pedagógica institucional. Netward, año 4, nro. 4, pp. 30-37.

Rosaldo, R. (1989). Cultura y verdad. México: Conaculta.

Ruddock, J. et al. (1996)."Student Voices: what can they tell us as partners in change?”. Scott K. y Trafford V.N. (eds.) Partners in Change: Shaping the Future. Middlesex: University Press

Sen, A. (1999). "Democracy as Universal Value", Journal of Democracy, nro. 10 , pp. 3-17. 


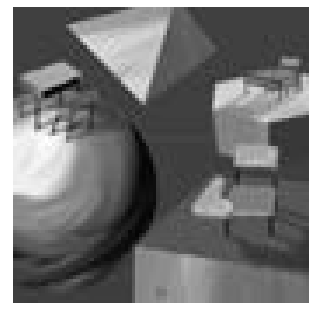

